\title{
RESEARCH DIRECTIONS
}

\section{From students to scientists: The impact of interactive engagement in lectures}

\author{
Craig McMillan ${ }^{1,2}$, Daphne Loads ${ }^{2} \&$ Heather A. McQueen ${ }^{1,2^{\star}}$ \\ ${ }^{1}$ School of Biological Sciences, University of Edinburgh, Edinburgh, Scotland, UK \\ ${ }^{2}$ Institute for Academic Development, University of Edinburgh, Edinburgh, Scotland, UK \\ *Corresponding Author: $\underline{\text { H.McQueen@ed.ac.uk }}$
}

Keywords: Active learning, interactive engagement, quecture, scientific skill-set, graduate attributes

\begin{abstract}
"Graduate attributes" are widely believed to be important in developing the scientific skill-set, with generic skills being viewed as more important than discipline-specific qualities. Importantly, students need opportunities to think and practice in ways akin to experts. The continued use of didactic lectures in university education often leads to the accumulation of superficial knowledge, and does not adequately train students to acquire the skills and attributes required of an effective scientist: critical thinking, an inquiring mind and creativity. We analysed active learning lecture strategies in a second year genetics course to determine their effectiveness in developing the scientific skill-set. These were found to be more beneficial than standard lecturing. Investigation of one of these strategies, the "quecture" (an adaptation of the flipped classroom), found that students did not view this method as being the most useful, despite being the most interactive. Our evidence suggests this student resistance to result from the requirement for prior preparation, perceived as an increased workload. We advocate the incorporation of active learning strategies in lectures to support the development of students' scientific skill-set and specifically advise the introduction of novel formats such as the quecture early in university level science education.
\end{abstract}

\section{Introduction}

Lectures that follow a traditional, didactic format do not train students effectively as scientists (National Research Council, 2003). Teaching occurring in this manner often only serves to transmit knowledge passively from the lecturer, whereby students learn by mere memorisation of facts (Nie and Lau, 2010). As a result, students that are taught predominantly in this style often only accumulate a mass of superficial knowledge, and therefore their ability as research scientists is far below the level that is required (Wood, 2009). Through rote learning, students may perform very well in assessments throughout their time at university. However when faced with "real world" problems and applications (e.g. designing an experiment, defending data to peers, collaborating across different specialties) three problems arise. Firstly, their conceptual understanding may be insufficient, and secondly, they may have little grasp of many "softer" skills that are necessary for scientific work due to the lack of any direct effort dedicated to developing them (Biggs, 1996). The third issue is that students are unwittingly excluded from learning by lecturers using discipline-specific language before students have full understanding of their meanings, leading to regurgitation without comprehension.

University educators must strive to teach more than just an ability to regurgitate facts; they must provide an opportunity for students to develop the various skills that are essential to allow the progression from novice to expert. Central to this development is allowing students to experience ways of thinking and 
practicing (WTP) like an expert (McCune and Hounsell, 2005). Discipline-specific knowledge is only a fraction of what comprises WTP, which focuses more on the bigger picture developing the qualities, skills, forms of discourse and attributes that are regarded as crucial to becoming an effective scientist. We introduce this as the "scientific skill-set", referring to everything that encompasses what makes a scientist. Universities themselves have taken action towards fostering a desirable skill-set within their students, with many devising a set of "graduate attributes" (GAs). GAs are qualities that all students, regardless of degree discipline, are expected to acquire by the time they graduate and are increasingly being seen as an obligate part of higher education (Barrie, 2007). Table 1 shows the GAs of the university where this study took place.

Traditional lectures do not provide an efficient learning environment for personal development and so are not seen to be conducive to allow growth of this scientific skillset (Bligh, 2000). Lectures contribute a large percentage of learning time for many courses and therefore need to be optimised to be as beneficial as possible, aiding students on the progression pathway. "Active learning" lecture methods do demonstrate aspects of the essential WTP principles central to meaningful student development resulting from the increased interaction experienced. Active learning covers a range of different types of activities from individual and group problem solving, to discussing ideas with peers, to interacting directly with the lecturer (Wood et al., 2016). Instances where students are involved in the deliberate practice of solving problems, or predicting outcomes, improve students' ability to "think scientifically" (Deslauriers et al., 2011). Furthermore, working in a group reflects the collaborative nature of science as researchers rarely work alone: they frequently debate experimental results, inform each other about procedures, and assess possibilities for future experiments (Tanner et al., 2003).

A common example of an active learning activity in lectures is Peer Instruction $(\mathrm{PI})$ as described by Mazur and Hillborn (1997). This practice consists of the lecturer posing a problem-based multiple choice question to the class, where students initially consider this individually and then electronically vote for their perceived correct answer (using automated response systems, for instance the 'Top Hat' programme), before they confer with their neighbours and vote again. The result is that a greater proportion of students select the correct answer after discussing the problem with their peers, as they engage in communicating their reasoning and are required to explain their conceptual understanding, and hence are able to learn from each other (Bates et al., 2006).

The "flipped classroom" is a way of structuring learning by predominantly dedicating lecture time to learning activities that are active and social. Students are required to prepare for the lecture by reading around the relevant topic with the class time focused on problem solving and discussions (Mazur \& Hillborn, 1997).

\begin{tabular}{|l|l|}
\hline \multicolumn{1}{|c|}{ Graduate Attribute } & \multicolumn{1}{c|}{ How useful is this for scientists? } \\
\hline Research and Enquiry & $\begin{array}{l}\text { Discovery by formulating and investigating questions and } \\
\text { theories }\end{array}$ \\
\hline Personal and Intellectual Autonomy & $\begin{array}{l}\text { Possessing the understanding and confidence to criticise or } \\
\text { defend relevant data }\end{array}$ \\
\hline Personal Effectiveness & $\begin{array}{l}\text { Maintaining high standards of work and seeking ways to } \\
\text { improve research performance }\end{array}$ \\
\hline Communication & Collaboration and dissemination of ideas and findings \\
\hline
\end{tabular}

Table $1 \mathrm{GAs}$ as set by one university noted alongside potential ways they are needed in a scientific context 
However, despite encouraging students to think more in-depth about the content, the flipped classroom does not necessarily address a student's own misconceptions and therefore may result in crucial gaps in their knowledge. In addition, there is a danger that the classical flipped classroom leaves the student to cover much of the material during independent study and thus may lead to significant gaps in understanding.

An adaptation that is currently being piloted, known as the 'quecture' (McQueen \& McMillan 2017), aims to address these problems by splitting the introduction of new information, such that basic concepts are learned in the preparation phase and more complex ideas are introduced during the lecturing phase. Also, and key to this method, time is built in during the lecture for students to formulate and discuss their own questions, which are addressed via a personal response system. The questions created are unique to each learner and represent the gaps in the framework of their individual knowledge. This method will encourage the development of students' scientific skill-set via the deliberate action of making predictions, discussing potential answers and devising further questions with peers.

A wealth of data is already available about how active learning methods improve conceptual understanding (Hake, 1998; Freeman et al., 2007; Cleveland et al., 2017), but there is a distinct lack of information on how these lecture strategies impact upon the development of the scientific skill-set or how much interaction in lectures is felt to be beneficial. In our study we looked to determine which skills are essential to becoming an effective scientist and how relevant the university's GAs are to this skillset. In addition, we looked at how students gauged the impact of active learning strategies in lectures upon the development of these skills.

\section{Methods}

\section{Interviewing Lecturers}

This project was carried out in the context of a 20-credit second year, second semester genetics course, which had twenty eight 50 minute lectures split between six instructors alongside four introductory or revision lectures. The main active learning activities during most lectures were multiple choice questions posed electronically to the class, sometimes designed around PI principles, with the quectures occurring in one lecture block only. A set of questions was posed to each lecturer on the course during individual interview, with the aims of establishing which skills they felt were essential to becoming a scientist, and gathering opinions on whether these were (or could be) promoted in lectures. Additionally, instructor familiarity with the university's GAs was explored before looking at their relevance with respect to the scientific skill-set, along with how relevant they were perceived to be in science education. Each interview was recorded and transcribed, before extraction of the key themes, which were compiled into a single document. Each lecturer is referred to as Instructor 1, 2, 3, 4, 5 or 6 . Instructor number also corresponds with lecture block number.

\section{Coding of Lectures}

To characterise the interactivity that occurs within lectures, an adaptation of the framework for interactive learning in lectures (FILL) developed by Wood et al. (2016) was used. The protocol focuses on two-way interactions that occur in lectures and considers how students experience activities. It also moves away from simply coding lectures in the binary mode of "active/interactive" or "passive/noninteractive" and considers the amount of time spent on such activities. The coding scheme (Table 2) describes the types of activity the student is involved in, which are denoted as either interactive, vicariously interactive or noninteractive. Coding of the lectures occurred in a contiguous fashion with only one activity assigned at any time. Student interactions with other students, with the lecturer, or with the material fall into the "interactive category". Although activities such as questions being asked of and by the lecturer will only directly involve a small number of students, their nature invites the rest of the students to contemplate how they would contribute if they were participating directly in the discussion. In essence, these students are "vicariously" involved in the dialogue, as they consider what their inputs would be, as opposed to passively waiting for the dialogue to conclude. A deviation was made from the original protocol 


\begin{tabular}{|c|c|c|c|}
\hline Type of Activity & Code & Description & Interactivity \\
\hline $\begin{array}{l}\text { Lecturer talking, } \\
\text { student listening }\end{array}$ & Ltalk & $\begin{array}{l}\text { Lecturer talking to the students. One-way } \\
\text { communication, no interaction }\end{array}$ & $\begin{array}{c}\text { Non- } \\
\text { interactive }\end{array}$ \\
\hline Lecturer question & LQ & $\begin{array}{l}\text { Lecturer asking students a question. Includes } \\
\text { questions answered by a student, questions } \\
\text { unanswered but where an answer was } \\
\text { sought, and rhetorical questions. Excludes PI } \\
\text { questions }\end{array}$ & $\begin{array}{l}\text { Vicariously } \\
\text { interactive }\end{array}$ \\
\hline Student question & SQ & $\begin{array}{l}\text { Students asking a question. Can be either } \\
\text { unprompted or prompted by the lecturer (e.g. } \\
\text { Are there any questions? }\end{array}$ & $\begin{array}{l}\text { Vicariously } \\
\text { interactive }\end{array}$ \\
\hline $\begin{array}{l}\text { Student silent } \\
\text { thinking }\end{array}$ & S-Think & $\begin{array}{l}\text { Students prompted to solve a problem } \\
\text { individually (for example, but not limited to, } \\
\text { during a } \mathrm{Pl} \text { episode) }\end{array}$ & Interactive \\
\hline $\begin{array}{l}\text { Student-student } \\
\text { discussion }\end{array}$ & SS-Diss & $\begin{array}{l}\text { Students discussing a problem with each } \\
\text { other (for example, but not limited to, during a } \\
\text { PI episode) }\end{array}$ & Interactive \\
\hline $\begin{array}{l}\text { Feedback on PI } \\
\text { voting }\end{array}$ & Feedback & $\begin{array}{l}\text { Displaying the results of a vote following a } \\
\text { clicker question }\end{array}$ & Interactive \\
\hline
\end{tabular}

Table 2 The FILL protocol. Codes for lecture activity and a description of what constitutes each code are highlighted (adapted from Wood et al., 2016).

by including rhetorical questions by the lecturer, which we believed to spark active thought in students. Any time dedicated to the introduction of Peer Instruction questions (which were posed through the medium of 'Top Hat') was included in the "Lecturer talking" (Ltalk) category, as in the lecture this is experienced as the instructor talking with students listening. Passive observations of demonstrations are reported as having a far reduced effect on student understanding in comparison to students that are involved in the demonstration, such as predicting the outcome (Crouch et al., 2004). Passive demonstrations are viewed as non-interactive as, again, this is how they are experienced. Despite the fact that there is no verbal interaction during the "Feedback" section, we include this in the interactive category as it completes the dialogue that had been created with the students. Further elaboration or explanation by the lecturer was denoted as one of the other codes as appropriate (e.g. Ltalk). Duration of all activities was rounded to the nearest 5 seconds. This protocol was used to analyse two lectures from each instructor's block. The analysis took place by listening to the recording of the lecture as it allowed for pausing, rewinding and confirming the timing of each interaction. At least one lecture from each instructor was attended prior to coding, to form a fuller understanding of each lecture style and format.

\section{Focus Groups}

Recruitment of students to participate in three focus group sessions was done using sign-up sheets; participation was completely voluntary. Conversation primers were developed and used to explore a variety of student perceptions within a specific topic of discussion for each focus group. The first one focused on students' perceptions of lecturing, what skills were necessary to be a scientist and any knowledge of their University's GAs. The second and third sessions focused on student perceptions of various lecture strategies used in the course, and opinions on increased interaction in lectures. The direct interaction of the focus group allowed for opportunities to elucidate answers, for follow-up questions to further probe responses, and to build upon the responses of others, creating a synergistic effect potentially resulting in data that may not have been uncovered in individual interviews. The three focus groups were attended by 3,1 and 3 students respectively. The focus groups were recorded to aid analysis, and participants were advised of this in line with our ethical approval. 


\section{Student Questionnaires}

Two questionnaires were created on Google Forms, with the choice and wording of the questions being informed by data gathered by the focus groups. The first was sent out to the previous year's students to gather retrospective opinions on the quecture format. The questionnaire contained nine multiple choice questions and two open ended questions, and had 40 respondents. The second was sent out to current students on the course, exploring their opinions on what skills are essential to be an effective scientist, their knowledge of graduate attributes and whether increased interaction in lectures benefits either or both of their learning and development of a scientific skill-set. There were nine multiple choice questions, two ranking questions, one open ended question and one likert question. There were 60 respondents. To encourage contribution in each questionnaire, it was advertised that one participant would be selected at random to win a £10 Amazon voucher. The questionnaires were delivered directly to the relevant student group via email. All responses were anonymised.

\section{Results}

\section{Perspectives of the essential skills to be an effective scientist}

In order to establish what are regarded as the key attributes within the scientific skill-set, two different viewpoints were analysed. The six course lecturers' responses are shown as a frequency table of what they perceive to be most important, taking into account word choice and paraphrasing (Table 3). The students' responses to relevant questions from the questionnaire were generated into a Wordle (Fig 1), with the size of text representing the frequency of answer.

\section{The role of graduate attributes within the scientific skill set}

It was widely agreed by staff and students that the university's GAs are appropriate in the process of becoming a scientist (Figure 2), with only a slight difference in their relative importance or relevance. Two-thirds of lecturers see them as "very relevant" and almost $60 \%$ of students regard them as "very important" with only 2 of 60 students feeling neutral.

\begin{tabular}{|l|c|}
\hline \multicolumn{1}{|c|}{ Skill } & Frequency \\
\hline Critical thinking & 4 \\
\hline Inquiring mind & 4 \\
\hline Imagination & 2 \\
\hline Communication & 2 \\
\hline Practical/Quantitation skills & 2 \\
\hline Problem Solving & 1 \\
\hline Independence of learning & 1 \\
\hline
\end{tabular}

Table 3 Opinions of what constitutes the scientific skill-set. Frequency table displaying all responses from the six lecturers and how many lecturers explicitly named a particular skill.

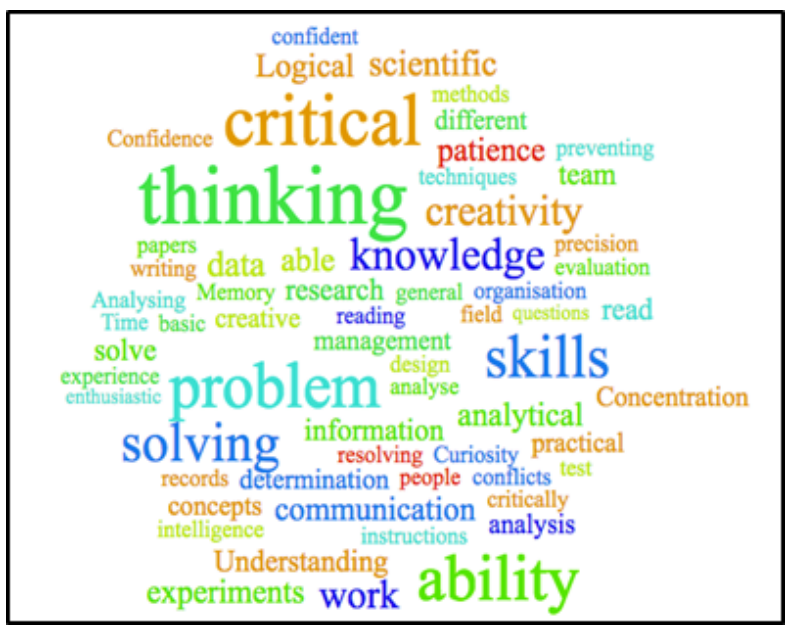

Figure 1 Opinions of what constitutes the scientific skill-set. Wordle generated from 60 students' questionnaire responses to the question "What skills do you feel are essential for becoming an effective scientist?"

\section{The role of graduate attributes within the} scientific skill set

It was widely agreed by staff and students that the university's GAs are appropriate in the process of becoming a scientist (Figure 2), with only a slight difference in their relative importance or relevance. Two-thirds of lecturers see them as "very relevant" and almost $60 \%$ of students regard them as "very important" with only 2 of 60 students feeling neutral. 

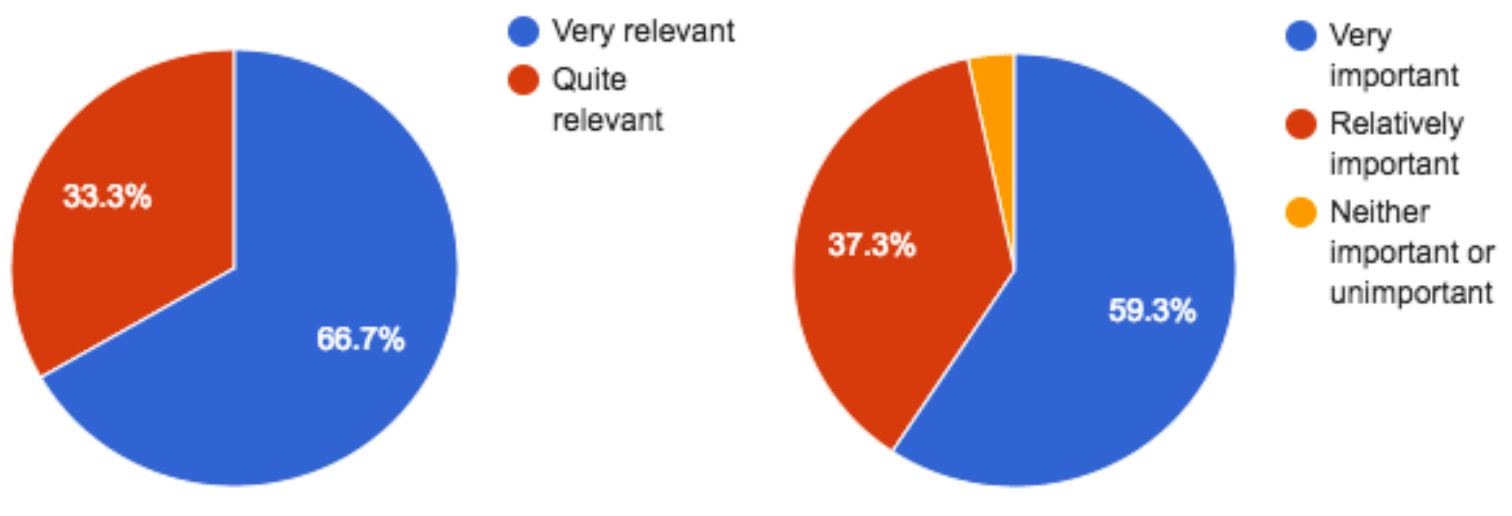

Figure 2 The perceptions of the importance of developing GAs to become an effective scientist for; (left) 6 course lecturers and (right) 60 students.

"Over the last year, do you feel you have improved any of these skills?"

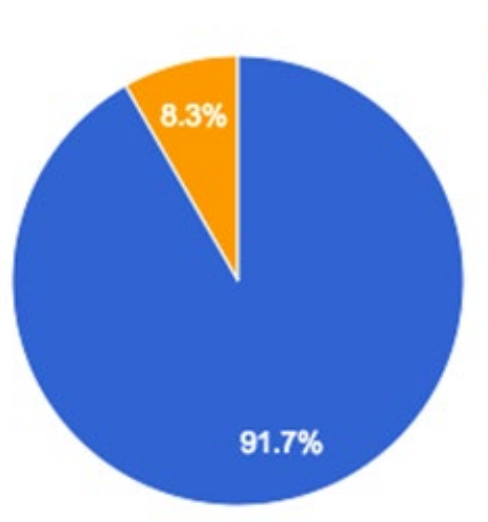

"Do you feel you feel you have improved any of these skills in LECTURES?"

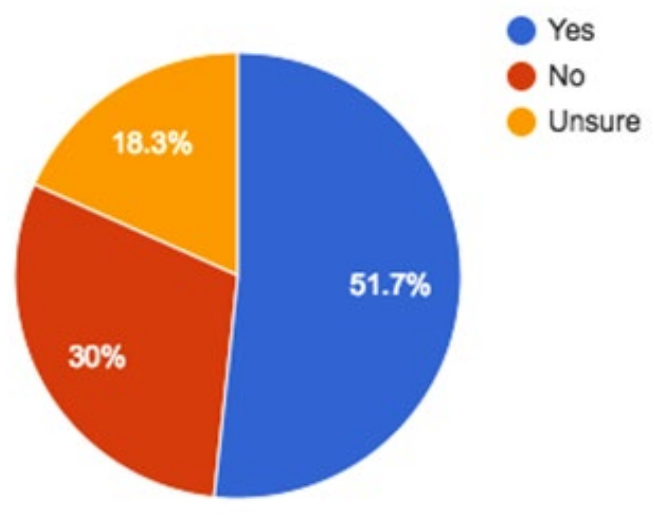

Figure 360 students' perceptions of whether or not they had developed the skills to be an effective scientist within last year; (left) in general and (right) in lectures.

\section{Development of the scientific skill-set}

Over $90 \%$ of students felt that they had improved their scientific skill-set over the past academic year, but only $51.7 \%$ of students felt any of this improvement had occurred in lectures (Figure 3).

\section{Characterising lecture interactions using the FILL protocol}

Following the coding of lectures based on the FILL protocol, the total proportion of each type of interaction in each lecture was determined (Table 4). Lecture block 4 (the quectures) was the most interactive with an average of $42 \%$ of lecture time dedicated to interactive and vicariously interactive activities, whilst lecture block 2 was the least interactive with an average of $8 \%$ similarly attributed. For a $50-$ minute lecture, this $34 \%$ difference represents 17 minutes. Despite the fact that the quecture was the most interactive format, on average $50 \%$ of the lecture was experienced as noninteractive.

\section{Student perceptions of increased interaction}

On the whole, students felt that increased interaction made a difference to their learning experience. Over $80 \%$ believed that it helped their conceptual understanding and over $60 \%$ believed it helped develop the scientific skill-set (Figure 4). 


\begin{tabular}{|l|c|c|c|c|}
\hline & \multicolumn{4}{|c|}{ Average proportion of lecture dedicated to each type of interaction (\%) } \\
\cline { 2 - 5 } & Interactive & Non-interactive & $\begin{array}{c}\text { Vicariously } \\
\text { interactive }\end{array}$ & Other \\
\hline Lecture block 1 & 22 & 61.5 & 9.5 & 7 \\
\hline Lecture block 2 & 0 & 91.5 & 8 & 0.5 \\
\hline Lecture block 3 & 9 & 79 & 11.5 & 0.5 \\
\hline Lecture block 4 & 26.5 & 50 & 16 & 7.5 \\
\hline Lecture block 5 & 6 & 89 & 5 & 0 \\
\hline Lecture block 6 & 7 & 89.5 & 3 & 0.5 \\
\hline
\end{tabular}

Table 4 The average percentage of each interaction category based on the FILL protocol for two lectures from each instructor

"How do you feel increased interaction in lectures impacts your understanding of concepts?"

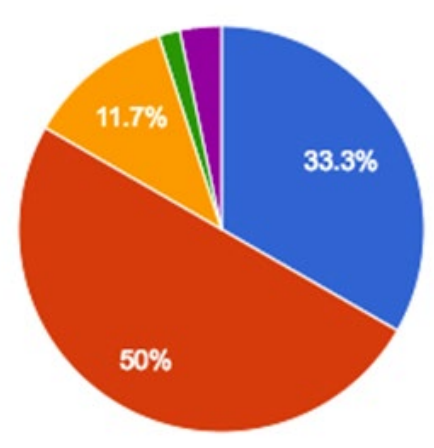

Strongly helps

Slightly helps

No impact

Slightly

hinders

Strongly

hinders

Figure 460 students' perceptions of how increased interaction impacts on; a) understanding of concepts and b) developing the scientific skill-set

Students were also asked to rank lectures in terms of interactivity and in terms of understanding (Figure 5) in order to gauge the degree of interaction they found most helpful. For each lecture block, in terms of both interaction and understanding, the results contained a defined peak. The only exception was for the perceived understanding in Lecture block 4 which shows a much flatter distribution.

An overall consensus of rankings from the students (Table 5) was created from the data in Figure 5, and allows for comparison with the
"How do you feel increased interaction in lectures impacts upon developing the skills to become a scientist?"

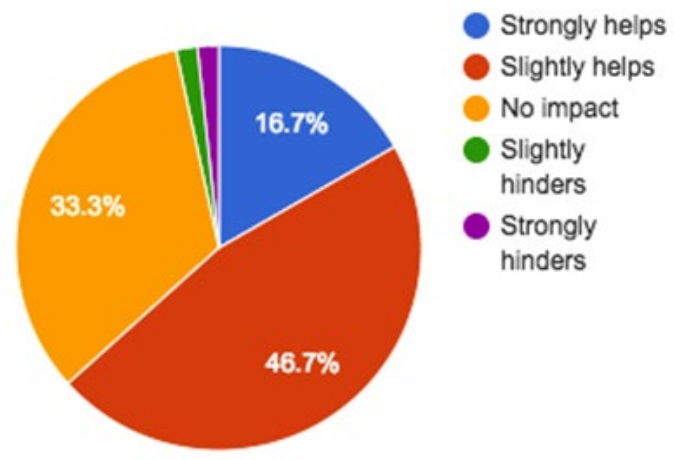

interactivity data gathered via the FILL tool. It was found that student perceptions of interactivity and the FILL data matched up exactly. The rankings of lecture blocks with respect to students' perceptions of interactivity correlated well with their ranking with respect to students' perceptions of understanding, with the exception that lecture block 4 was first in terms of interaction but third in terms of understanding. Therefore, there was a general trend towards correlation between interaction and understanding. 
From students to scientists: The impact of interactive engagement in lectures

"Rank the lecture block from most to least INTERACTIVE $\left(1^{\text {st }}=\right.$ most interactive lecture block, $6^{\text {th }}=$ least interactive block)."

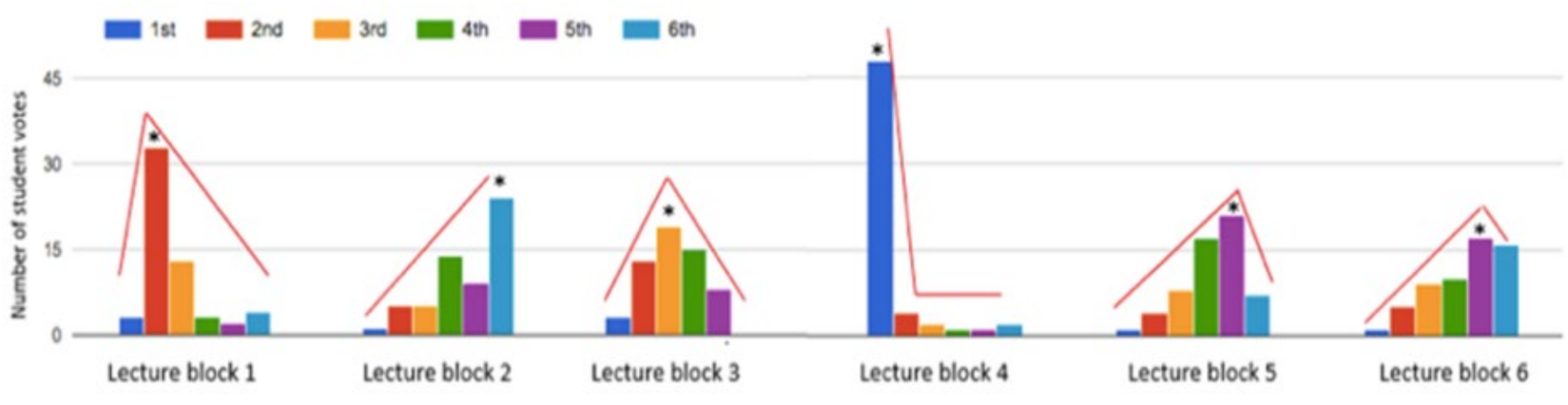

"Rank the lecture block by where you felt you gained the greatest understanding of concepts DURING the lectures $\left(1^{\text {st }}=\right.$ most understanding, $6^{\text {th }}=$ least understanding)."

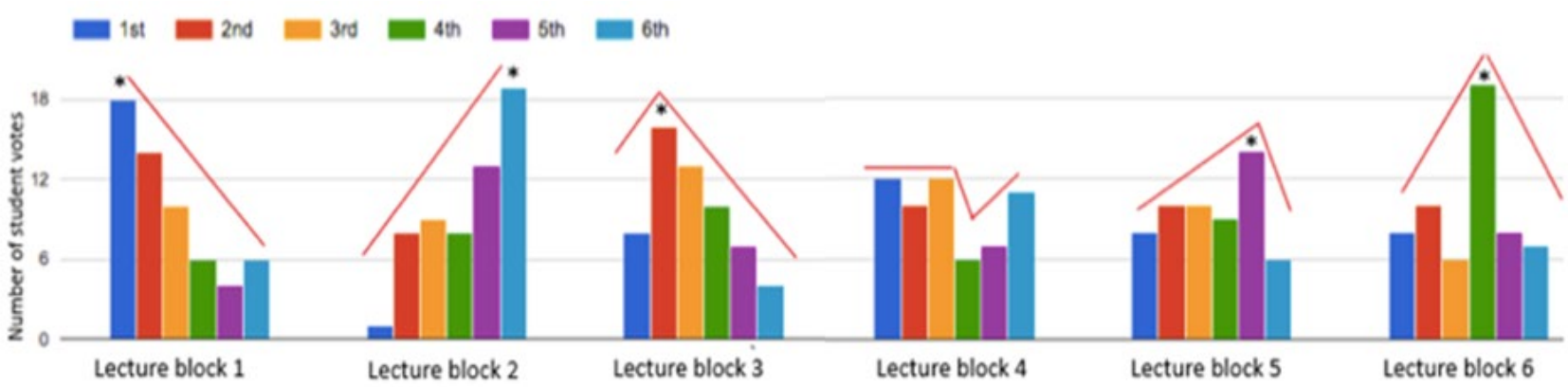

Figure 5 Breakdown of the votes students ranked the lecture blocks in terms of (top) interactivity and (bottom) understanding. The red line indicates the trend of voting and the asterisk highlights the clear peak, where one is present

\begin{tabular}{|c|c|c|}
\hline $\begin{array}{l}\text { Ranking of lecture } \\
\text { block students found } \\
\text { to be most interactive }\end{array}$ & $\begin{array}{l}\text { Observed average \% } \\
\text { of lecture spent on } \\
\text { interactive activities } \\
\text { (FILL) }\end{array}$ & $\begin{array}{l}\text { Ranking of lecture } \\
\text { block students felt } \\
\text { they gained the most } \\
\text { understanding }\end{array}$ \\
\hline $1^{\text {st }}$ - Lecture block 4 & $42 \%$ & $1^{\text {st }}$ - Lecture block 1 \\
\hline $2^{\text {nd }}-$ Lecture block 1 & $31.5 \%$ & $2^{\text {nd }}-$ Lecture block 3 \\
\hline $3^{\text {rd }}-$ Lecture block 3 & $20.5 \%$ & $3^{\text {rd }}$ - Lecture block 4 \\
\hline $4^{\text {th }}$ - Lecture block 5 & $11 \%$ & $4^{\text {th }}$ - Lecture block 5 \\
\hline $5^{\text {th }}$ - Lecture block 6 & $10 \%$ & $5^{\text {th }}$ - Lecture block 6 \\
\hline $6^{\text {th }}-$ Lecture block 2 & $8 \%$ & $6^{\text {th }}-$ Lecture block 2 \\
\hline
\end{tabular}

Table 5 Relationship of interactivity in lectures and how much students felt they learned. Lecture blocks are coloured for simplicity of comparison. Percentage of time spent on interactive activities refers to the combined proportion of time that can be classified as interactive or vicariously interactive. The rankings were determined by totalling the sum of frequency of student votes by the ranking number which they voted for. 
"What is your preferred style of lecture?"

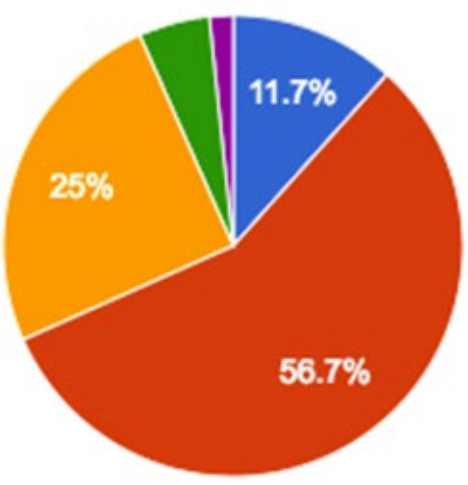

"Would you like to see more quectures in your course?"

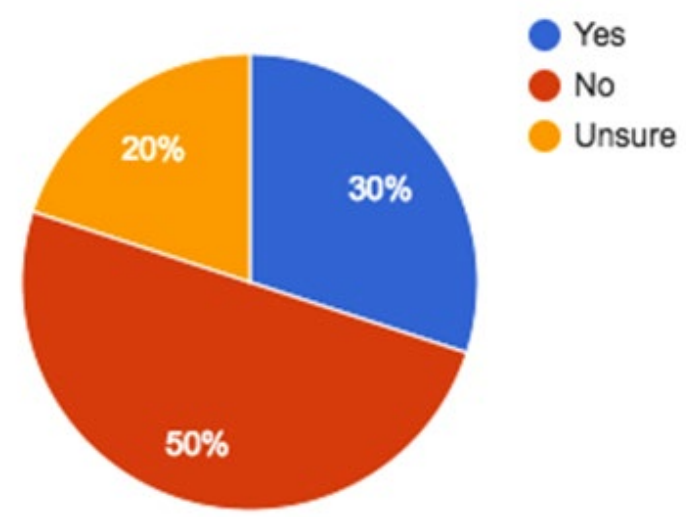

Figure 6 Student lecture style preferences. (left) The preferred style of lecturing of 60 students (right) The positivity towards the inclusion of more quectures in their courses of 40 students.

"On average, how much preparation did you do prior to each quecture last year?"

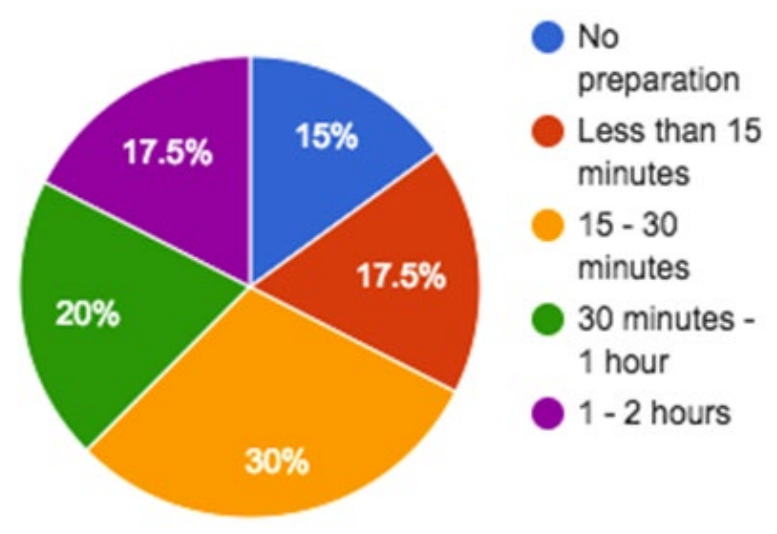

"On average, how much preparation did you do prior to each traditional lecture last year?"

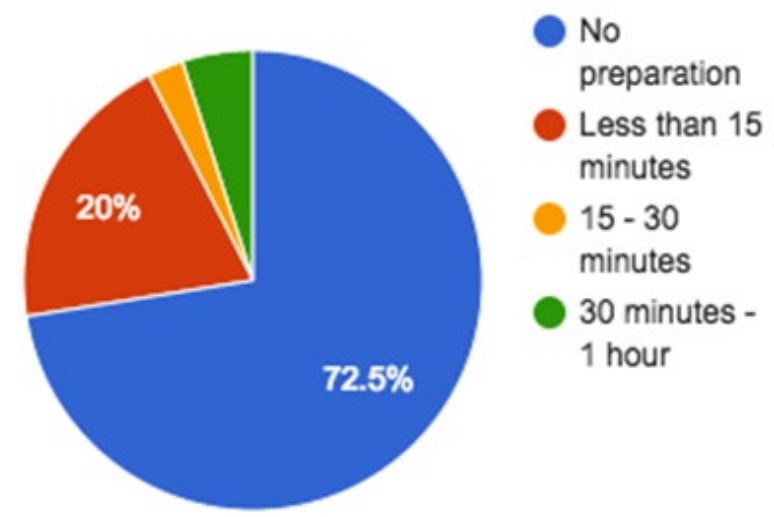

Figure 7 Time students spent preparing for (left) quectures and (right) traditional lectures

\section{Student opinions of the lecturing styles}

Lectures with interactive elements (i.e. 'Top Hat' questions) were the clear favourite strategy, with $56.7 \%$ naming this as their preferred style and $25 \%$ stated that the quecture was their preferred style of lecture, with $30 \%$ saying that they would like to see more quectures in their courses (Figure 6).

\section{Student preparation for the quecture}

The way that students approached both standard lectures and quectures was analysed (Figure 7). A difference in preparation time between these strategies was evident with over $70 \%$ of students doing no preparation at all for standard lectures, and $20 \%$ doing less than 15 minutes. The recommended preparation time for the quecture was one hour, but only $37.5 \%$ of students prepared for over 30 minutes.

\section{Discussion}

\section{Establishing the skills needed to be an effective scientist}

With the training received by students considered to be inadequate in order to develop effective scientists (National Research Council, 2003), we have taken steps to first establish perspectives of what makes an effective scientist. The Researcher Development Framework (RDF) (Vitae, 2014) looks at the skills required to be a successful $\mathrm{PhD}$ researcher (https://www.vitae.ac.uk/vitaepublications/rdf-related/researcher- 
development-framework-rdf-vitae.pdf/view).

Whilst not all scientists will necessarily be researchers, or indeed plan to undertake a $\mathrm{PhD}$, this framework displays the variety of skills that are necessary to be successful in this area and so gives a solid foundation from which to draw inferences. Comparing this framework to our results, we see some interesting overlaps. The RDF does not rank any one skill as more important than another; it sees all skills as being equally necessary to develop in full, in order to be effective. Both lecturers and students most valued "critical thinking", which is defined as the objective analysis and evaluation of information in order to form a judgement and comes under the heading of "Cognitive abilities" in the RDF (Figure 1). The joint most-frequent answer from the lecturers, "inquiring mind", refers to the need to question received information and having a desire continually to learn. This skill comes under the heading of "Creativity" in the RDF, which features strongly in the students' responses and, if the definition is extended to include the common synonym "Imagination", then it is also seen in the lecturers' responses. Analysing these three viewpoints we find strong overlap in the skills believed to be required, but interestingly most responses named generic skills as being the most important to develop, with discipline-specific skills nested underneath. Critical thinking, creativity, communication and possessing an inquiring mind are skills required by most disciplines. Key within these findings is the agreement that factual knowledge is only a small piece of a very large puzzle in what constitutes effectiveness as a scientist. What is vital is having the ability to form objective judgements, to defend or criticise data, and to possess the creativity leading to the design of novel ideas or experiments.

\section{Graduate attributes are important and relevant to the scientific skill-set}

There is strong overlap between the GAs (Table 1) and the skills mentioned in Table 3 and Figure 1. For example, "Research and Enquiry" extends the idea of an inquiring mind, with "Personal and Intellectual Autonomy" linking to the ability to think critically. "Personal Effectiveness" comprises Domain B of the RDF and "Communication" features across all three viewpoints. It is perhaps unsurprising, therefore, that there is near universal agreement that GAs are important and relevant to the scientific skill-set. This again confirms the importance of numerous, generic skills within scientific practice and the necessity to allow a platform within higher education where they can be learned. These findings could inform teaching practices from here forward, by focusing on a greater integration of teaching methods that promote the development of GAs, such as increasing group discussion within lectures for example, to improve the communication and critical thinking skills required to become an effective scientist.

\section{Investigation of lecture strategies to promote the scientific skill-set}

The predominant lecture strategies present in the course studied were standard lecturing, the employment of 'Top Hat' questions designed around $\mathrm{PI}$ principles and the quecture, an adaptation of the flipped classroom. We looked at the duration of time spent on these interactive exercises between lecture blocks to assess the impact of interaction on student development. The last two strategies are examples of active learning methods (Mazur \& Hillborn, 1997; McQueen \& McMillan, 2017) and increase the level of interaction experienced by students in the lecture, which previous studies have shown to be very effective in aiding learning (Hake, 1998; Freeman et al., 2007; Cleveland et al., 2017). It was determined that, on the whole, students perceive increased interaction as a result of these methods to be beneficial to both conceptual understanding and personal growth. Active learning methods do provide an opportunity to think and practice like an expert, allowing the development of necessary scientific skills (McCune \& Hounsell, 2005; Deslauriers et al., 2011; Tanner et al., 2003) and thereby work to facilitate the progression toward becoming an expert.

The results of our FILL analysis (Table 4) confirm that a lecture should not be simply assigned the dichotomy of either active or passive, as even the quectures or lectures rich with Tophat questions do have extended periods of time with non-interactive elements. Whilst identifying a common optimum proportion of time that should be spent on interactivity would be difficult (Wood et al., 2016), further research could aim to provide some ball-park guidance as to the most 
effective learning environment to allow enhanced promotion of the scientific skill-set.

One might ask why the most interactive lecture format, the quecture, did not result in the greatest perceived understanding. Survey data suggested that adequate preparation for the quecture was not achieved, with the required hour of prior study being reached by only a very small percentage of the class. This suggests that the vast majority of students were arriving at the quecture underprepared, which would mean that they did not have a firm grasp of the content and so could not apply the knowledge in the way that was asked of them. These students thereby missed out on the opportunity for personal and professional growth. Lack of engagement negates all benefits of the flipped classroom model (Abeysekera \& Dawson, 2015) and may lead to the perception that the learning method is ineffective. The range of preparation times reported might be expected to result in a wide range of perceived understanding, and could possibly explain why there was no defined peak in the rankings of students' perceived understanding for this lecture block. So what may be causing this resistance to preparation? Bates and Galloway (2012) report a first year physics class where all lectures are flipped, requiring preparation, which has resulted in increased normalised learning gains and deeper conceptual understanding. The focus in this project is a second year, second semester course and so, unlike this physics course, students have progressed through early undergraduate studies with no habit of prior preparation. Thus, a new lecturing style combined with the requirement of extra work may not be welcomed by all students, many of whom (through habit, poor time management or perhaps even stubbornness) will not participate in preparation. A potential solution to this would be to introduce the quectures from semester one of first year. Doing this would establish engaged learning habits from the outset and lend itself to further study of how this interactive experience impacts upon student learning and skill development.

\section{Declaration}

The authors declare no conflicting interests concerning this work. The work was conducted in an ethical and responsible manner aiming to comply with all relevant legislation, and was approved by the local University ethics committee.

\section{References}

Bates, S.P., Howie, K. \& Murphy, A.S. (2006). The use of electronic voting systems in large group lectures: Challenges and opportunities. New Directions in the Teaching of Physical Science 2, 8-25. Available from: https://journals.le.ac.uk/ojs1/index.php/newdirections/article/view/426

Bates, S. \& Galloway, R. (2012). The inverted classroom in a large enrolment introductory physics course: a case study. Proceedings of the HEA STEM learning and teaching conference (Vol. 1). Available from:

https://www2.ph.ed.ac.uk/ rgallowa/Bates Ga lloway.pdf

Barrie, S.C. (2007). A conceptual framework for the teaching and learning of generic graduate attributes. Studies in Higher Education 32, 439-458.

DOI: $10.1080 / 03075070701476100$

Biggs, J.B. (1996). Enhancing teaching through constructive alignment. Higher Education 32, 347-364.

DOI: $10.1007 / \mathrm{BF} 00138871$

Bligh, D. (2000). What's the use of lectures? San Francisco, CA: Jossey-Bass.

Cleveland, L.M., Olimpo, J.T. \& DeChennePeters, S.E. (2017). Investigating the Relationship between Instructors' Use of Active-Learning Strategies and Students' Conceptual Understanding and Affective Changes in Introductory Biology: A Comparison of Two Active-Learning Environments. CBE-Life Sciences Education 16, 1-10.

DOI: $10.1187 / \mathrm{cbe} .16-06-0181$

Deslauriers, L., Schelew, E. \& Wieman, C. (2011). Improved learning in a large-enrollment physics class. Science 332, 862-864.

DOI: 10.1126/science.1201783

Freeman, S., Eddy, S.L., McDonough, M., Smith, M.K., Okoroafor, N., Jordt, H. \& Wenderoth, M.P. (2014). Active learning 
From students to scientists: The impact of interactive engagement in lectures

increases student performance in science, engineering, and mathematics. Proceedings of the National Academy of Sciences 111, 84108415. DOI: 10.1073/pnas. 1319030111

Hake, R. R. (1998). Interactive-engagement versus traditional methods: a six-thousandstudent survey of mechanics test data for introductory physics courses. American Journal of Physics 66, 64-74. DOI: 10.1119/1.18809

Mazur, E. \& Hilborn R.C. (1997). Peer instruction: A user's manual. Physics Today 50, 68-69. DOI: 10.1063/1.881735

McCune, V. \& Hounsell, D. (2005). The development of students' ways of thinking and practising in three final-year biology courses. Higher Education 49, 255-289. DOI: 10.1007/s10734-004-6666-0

McQueen, H.A., McMillan C. (2017). Introducing the Quecture for personalised constructive learning (submitted for publication in Active Learning in Higher Education)

National Research Council. (2003). BIO2010: Transforming undergraduate education for future research biologists. Washington DC: National Academies Press.

Nie, Y. \& Lau, S. (2010). Differential relations of constructivist and didactic instruction to students' cognition, motivation, and achievement. Learning and Instruction 20, 411-423.

DOI: 10.1016/j.learninstruc.2009.04.002

Tanner, K., Chatman, L.S. \& Allen, D. (2003). Approaches to cell biology teaching: cooperative learning in the science classroom-beyond students working in groups. Cell Biology Education 2, 1-5.

DOI: $10.1187 / \mathrm{cbe} .03-03-0010$

Wood, W. B. (2009). Innovations in teaching undergraduate biology and why we need them. Annual Reviews of Cell and Developmental Biology 25, 93-112. DOI: 10.1146/annurev.cellbio.24.110707.175306

Wood, A.K., Galloway, R.K., Donnelly, R. and Hardy, J. (2016). Characterizing interactive engagement activities in a flipped introductory physics class. Physical Review Physics Education Research, 12(1), p.010140. DOI: 10.1103/PhysRevPhysEducRes.12.010140 